\title{
The Impact of the Financial and Economic Crisis on Turnover Intention in the U.S. Federal Government
}

\author{
Jan Wynen ${ }^{1}$ and Sophie Op de Beeck ${ }^{2}$ \\ KU Leuven, Faculty of Social Sciences, Public Management Institute
}

\begin{abstract}
Using data from the U.S. Federal Employee Viewpoint Survey, this article seeks to provide an insight in the effect of the financial and economic crisis on turnover intention within the U.S. federal government. By constructing panel data and applying a first difference estimator the effect of the crisis on turnover intention is examined, while dealing with a possible issue of endogeneity. Not only does this approach allow us to examine the effect of the crisis, but it also enables us to analyze whether the specific effect of independent variables identified by turnover literature has changed due to the crisis. Results highlight that the crisis has a negative impact on turnover intention, while the effects of pay, training, and gender on turnover intention appear to have changed.
\end{abstract}

Keywords: turnover intention, financial and economic crisis, public sector

\footnotetext{
${ }^{1}$ Corresponding author: Jan Wynen, KU Leuven, Faculty of Social Sciences, Public Management Institute, Parkstraat 45 bus 3609, 3000 Leuven, Belgium. Email: jan.wynen@soc.kuleuven.be

${ }^{2}$ Sophie Op de Beeck, KU Leuven, Faculty of Social Sciences, Public Management Institute, Parkstraat 45 bus 3609,300 Leuven, Belgium. Email: sophie.opdebeeck@soc.kuleuven.be
} 


\section{Introduction}

Turnover among employees within public sector organizations has been a constant concern for at least the past 20 years (Pitts, Marvel \& Fernandez, 2011). Positive as well as negative aspects of turnover have been studied (Meier \& Hicklin, 2007; Pitts, Marvel \& Fernandez, 2011). While some turnover is normal and even considered important for the health and viability of an organization in the long run (Dalton \& Todar, 1979), turnover can also lead to higher costs and disruptions of the normal flow of activities (Becker, 1978). More precisely, turnover can give rise to costs related to the loss of the performance and expertise of the employee, separation costs, recruitment costs, training costs, and lost productivity costs (Moynihan \& Landuyt, 2008; Grissom et al., 2012; Kellough \& Osuna, 1995; Lambert \& Hogan, 2009). Furthermore, replacing employees becomes more difficult since talents are scarce due to the upcoming shortage arising from retirement (Hatum, 2010). Consequently, the underlying bias of turnover research is that voluntary turnover is mostly a negative outcome for an organization.

In recent literature (Wynen et al., 2013; Pits, Marvel \& Fernandez, 2011) turnover has been conceptualized as the result of an employee decision making process related to (1) individual demographic and personal factors and (2) organizational factors. Newly proposed models are often an extension or refinement of these models, which are considered as the basis of turnover theory within the field of public management. Despite wide agreement on core models, it is still important for researchers to consider other factors besides individual and organizational characteristics as reasons for employee turnover. This article therefore seeks to provide a better empirical understanding of the causes of turnover in the public sector while taking an external factor, more precisely, the effect of the financial and economic crisis, into account.

Unprecedented events that took place in late 2008 in the U.S. market for sub-prime mortgages escalated to global proportions leading to the global economic recession (Wickramasinghe \& Perera, 2011; Stefaniak et al., 2012). This financial and economic crisis has strongly affected both the public and the private sector. Although there exists some empirical literature on the effect of the economic and financial crisis on job insecurity and turnover in the private sector (e.g. Battisti \& Deakins, 2011; Suzuki, 2010), such literature is still lacking for the public sector.

By constructing panel data using different waves from the U.S. Federal Employee Viewpoint Survey and by applying a first difference estimator, this article examines the 
antecedents of turnover in the public sector while taking the effect of the financial and economic crisis into account. Panel data allows us to examine the effect of independent variables over several years, while a first difference estimator is particularly interesting in the sense that this approach allows us to address the problem of omitted variables and, consequently, endogeneity.

The remainder of this paper is organized as follows: section 2 describes the theoretical underpinnings, while section 3 describes the data and offers some descriptive statistics. The used methodology as well as our main findings is discussed in section 4 , which is followed by some concluding remarks.

\section{Determining public sector turnover intention}

A growing body of literature in organization theory and public administration points to a number of common factors associated with turnover. In line with Moynihan and Landuyt (2008), our approach derives from the assumption of March and Simon (1958) that intention to leave the U.S. federal government depends on the factors that influence an employee's desirability and ease of movement. We distinguish three main categories of determining factors for turnover intention: (a) external environmental factors (b) individual demographic and personal characteristics, and (c) organizational and work-related elements. In Figure 1, this set-up is visually presented. It is, however, not our intention to discuss all possible determinants of employee turnover. Instead, we will focus on variables that will be incorporated in the subsequent empirical analysis. Based on the turnover literature, we develop hypotheses for each of the factors considered. ${ }^{3}$

Please include Figure 1 here

\subsection{The financial and economic crisis}

Although less widely studied, several external factors can be identified to be influencing employee outcomes, such as unemployment rate, accession rate, and union presence (Cotton $\&$ Tuttle, 1986). In this study, we account for the effect of the financial and economic crisis

\footnotetext{
${ }^{3}$ The factors discussed here are applicable to turnover intention in general. Yet the focus of this article solely lies on the intention to leave the U.S. federal government. Nevertheless the processes affecting turnover intention in general will also be of use when explaining the intent to leave the U.S. federal government in particular.
} 
on turnover intent among U.S. federal government employees. The financial and economic crisis has many implications for both organizations and individual employees. Under the rhetoric of "doing more with less", the focus of organizations has been on reducing costs. On an individual level, this can lead to feelings of job insecurity among employees. Job insecurity, in turn, is found to be related to various work-related attitudes, such as organizational commitment, job satisfaction, and intent to quit. More specifically, employees who perceive alternative job opportunities are more likely to leave their organization in times of crisis (Adkins et al., 2001; Greenhalgh \& Rosenblatt, 1984). Overall, this would mean that the financial and economic crisis is positively related to turnover intention. However, the arguments supporting this hypothesis are valid primarily for private sector employment. We believe a different logic applies for public sector employees. As the economic downturn often results in job loss and may affect people's perceptions on the stability of their employers (Greenhalgh \& Rosenblatt, 1984), job security gains importance and becomes highly valued among employees. Compared to the private sector, government generally offers more employment stability and job security. As such, several studies have found that people looking for job security prefer public sector employment (Baldwin, 1991; Lewis \& Frank, 2002; Vandenabeele, 2008). Also, “civil service protections make dismissals more difficult in government than in non-unionized private firms, and layoffs are uncommon, since government agencies downsize less frequently than private firms and almost never die" (Lewis \& Frank, 2002: 396). In addition, while measures such as pay freezes or cuts are implemented in the private sector to counteract the effects of the economic crisis, wages generally remain stable in public organizations (Eurofound, 2012). Considering these arguments, government becomes more attractive as an employer in times of crisis. Nevertheless, public organizations are also impacted by the recession and are pressured to introduce austerity measures, including a reduction of their workforce. This is demonstrated by the fact that "federal, state and local governments [in the U.S.] now employ 500,000 fewer workers than they did on the eve of the recession in 2007" (New York Times, February 26, 2013). However, to achieve these cutbacks, governments often fall back on hiring freezes, personnel ceilings, and reductions-in-force through attrition. Contrary to layoffs, attrition is a preferred method for workforce reduction because the organization simply does not fill the positions left vacant after people leave for their normal reasons. As such, it is considered to be more humane and, hence, creates less insecurity (Cayer, 1986). Altogether, during economic turbulent times the public sector is perceived as a more attractive employer compared to the private sector. Hence, we hypothesize that employees currently working in the federal 
government will be less inclined to leave their 'secure' position than before the recession started.

\subsection{Individual factors}

As personal characteristics may influence someone's attitudes and behavior, a number of typical individual factors are included in our study. These are gender, age, and length of service in the federal government.

Gender. Literature on the relationship between sex and turnover behavior shows inconclusive results. A majority of studies finds that women are more likely to leave their organization (e.g. Martin, 1979; Valcour \& Tolbert, 2003). Nevertheless, several studies indicated turnover intention to be lower for women (e.g. Lee \& Whitford, 2007), while others found no relationship between gender and intent to leave (e.g. Dowding \& John, 2008). Either way, the possible gender difference in turnover has several underlying explanations. According to the traditional assumption, women have higher turnover rates than men due to family responsibilities such as child care and household maintenance (Kellough \& Ossuna, 1995; Lewis, 1991; Moynihan \& Landuyt, 2008). Currently, however, the available work-life arrangements (cf. infra) have made women less likely to leave their organization (Moynihan \& Landuyt, 2008). Also, the fact that female employees are often clustered in lower lever, lower paying positions may lead to a higher likelihood of turnover (Kellough \& Ossuna, 1995). Finally, Moynihan and Landuyt (2008) argue for a distinct relationship between gender and turnover in the public sector. They state that there are several characteristics of public sector employment which make it a more attractive setting for women than the private sector, including a considerable progress in the representation of women (Choi, 2009; Llorens et al., 2008), lower wage penalties (cf. wage gap between men and women; e.g. Gornick \& Jacobs, 1998; Llorens et al., 2008), and a higher likelihood of finding work-life balance (Buelens \& Van den Broeck, 2007). Considering everything, we hypothesize that women are less likely to leave the federal government. In search for job security, women will be even less inclined to leave the federal government at the emergence of the financial and economic crisis.

Age. Another factor often examined in turnover research is age. In general, a negative relationship is assumed between age and turnover intention (Lewis, 1991; Sousa-Poza \& Henneberger, 2004), as older employees tend to perceive a lower ease of movement (Leggatt, 1979). According to the life cycle stability hypothesis, older employees with family obligations are more settled, they have a clearer idea of what they want to do, and, hence, they 
are less likely to leave (Lewis, 1991; Moynihan \& Landuyt, 2008). Also, older employees will be more attached to a particular employer as they have developed firm-specific knowledge and skills. Overall, older employees have more to lose from changing employers and will therefore have a lower intention to leave (Valcour \& Tolbert, 2003). Altogether, we predict that age is negatively related to turnover intention. This hypothesized effect will most likely be confirmed or become even stronger in a crisis. In any kind of labor market, older employees may struggle to get a new job (Bendick et al., 1999). During a financial and economic crisis, where job opportunities are scarce and unemployment rates are high, older employees are likely to find it even more difficult to find a job. Hence, we assume they will be less inclined to leave their current organization in times of crisis.

Length of service in the federal government. Age and length of service are evidently interrelated. Nevertheless, both are included in our analysis as the theoretical underpinnings relating them to turnover are different (Moynihan \& Landuyt, 2008). In general, longer serving employees will have a greater commitment to the organization as greater tenure implies higher long-term investments, such as firm-specific training, pay, and seniority (Kellough \& Osuna, 1995; March \& Simon, 1958; Martin, 1979; Muchinsky \& Morrow, 1980; Lambert \& Hogan, 2009; Moynihan \& Landuyt, 2008). The greater an employee's length of service, the more difficult it will be for him/her to leave the organization. As a result, we assume an inverse relationship between length of service and turnover intention, which we believe will also hold under circumstances of a financial and economic crisis.

Overall, the individual factors discussed above are assumed to be negatively related to turnover. This means that we hypothesize women, older employees, and longer serving employees to be less likely to leave their current position in the federal government. In addition, we assume that this inverse relationship will also hold, or may even be reinforced, during the financial and economic crisis as labor market conditions for these groups in particular are likely worse than before.

\subsection{Organizational factors}

Several organizational factors, denoting the interaction between employees and their job or organization, may explain turnover behavior. In line with person-environment fit theory (Schneider et al., 2000), it is found that a misfit between an employee and his/her job or work environment can lead to turnover intentions (Galletta et al., 2011). Various organizational factors, be it job characteristics, personnel policies or the work environment in general 
(Moynihan \& Landuyt, 2008), are considered to be a component of one key predictor of turnover intention, i.e. job satisfaction (Lambert \& Hogan, 2009; Mobley et al., 1979; Warr et al., 1979). Job satisfaction is "the extent to which organizational members have a positive affective orientation toward membership in the system" (Martin, 1979: 315). Our study, however, doesn't contain job satisfaction as a separate explaining factor of turnover. We do include several elements associated with job satisfaction, such as attitudes towards pay, worklife balance, and supervision (cf. infra), which allows us to examine the relationship between job satisfaction and turnover intention in more detail. Overall, job satisfaction is assumed to be negatively related to turnover, often mediated by organizational commitment (Battistelli et al., 2013; Cotton \& Tuttle, 1986; Lambert \& Hogan, 2009). The following variables are included in our study: workload, pay, promotion, work-life balance, training, and supervisor support.

Workload. Employees are more susceptible to emotional and physical burnout when they have a higher workload (Brannon et al., 2002). Aspects of the job, such as workload, related to burnout are considered to increase the intent to leave the current position (Kim, 2005). Consequently, we hypothesize that there is a positive relationship between a greater workload and turnover intention. Austerity measures, resulting from the financial and economic crisis, often imply employees to do more with less (cf. supra) and, hence, increases the workload. Despite this higher workload, though, government employees still experience the benefits of a relatively 'secure' position, making them less inclined to leave the organization.

Pay. Several personnel policies, such as pay, career opportunities, work-life balance and training (cf. infra), are expected to play a role in reducing turnover (Moynihan \& Landuyt, 2008). In motivating employees, extrinsic awards, such as pay, are essential (Smith, 2005). As a result, several studies have found higher pay levels or pay satisfaction to be crucial in retaining employees (e.g. Cotton \& Tuttle, 1986; Lewis, 1991; Weaver, 2012). Overall, we assume that the satisfaction with the current pay will be inversely related to the probability of leaving the federal government. The financial and economic crisis, however, has put increased pressure on employees' pay, resulting in measures such as pay moderation, pay freezes or cuts. These are detrimental to motivation in the workplace, which may cause the best workers to leave the organization. 'Fortunately', a study on EU countries generally found pay levels to remain stable in the public administration sector (Eurofound, 2012). Also, we believe pay may be a less important factor to employees in times of crisis and, hence, plays a smaller role in predicting turnover intentions. 
Promotion. Dissatisfaction with promotion, be it the promotional process, perceived opportunities or actual advancement, is often cited as a primary cause of turnover (Carson et al., 1994; Cotton \& Tuttle, 1986). Considered as an expression of individual recognition and career improvement, promotional opportunities are likely to reduce an employee's intent to leave (Doering \& Rhodes, 1996; Grissom et al., 2012). In general, we hypothesize that employees perceiving opportunities for promotion are expected to be less likely to leave their organization. Given the financial and economic crisis, we predict that the possible effect of promotional opportunities on turnover intention will be smaller because other factors, such as job security, prevail over financial or personal gain.

Work-life balance. According to social exchange theory and organizational support theory, arrangements supporting the balance between work and family commitments may reduce turnover intention (Battistelli et al., 2013; Smith, 2005; Lee \& Hong, 2011). Governments, especially, are still perceived to be leaders in the area of work-life balance (Kenexa, 2012). As a result, employees working in a public organization have a greater potential to find a good work-life balance and, hence, will be even less inclined to leave their position (Moynihan \& Landuyt, 2008). In a recent study, however, Lee and Hong (2011) found that not all work-life policies are equally significant in predicting turnover, suggesting that the existence of a causal relationship is dependent on the type of policies that are available in the organization under study. Bearing in mind this nuance, we cautiously predict that the existence of work-life policies reduces turnover intention. Again, the effect of worklife policies may possibly play a lesser role in predicting turnover under circumstances of crisis. Nevertheless, given governments' preferable status on work-life balance, employees will be even less likely to leave the federal government during a financial and economic crisis.

Training. An organization's personnel policy can also influence turnover rates through employee development programs. The direction of the relationship between training and turnover is, however, inconclusive as there are two conflicting effects at play (Moynihan \& Landuyt, 2008). On the one hand, training fosters a sense of employee loyalty to the organization and is therefore found to reduce turnover (Curry et al., 2005). On the other hand, training investments may increase employees' knowledge and skills, enhancing their employability. As such, employees are more capable of finding another job as they are more attractive to other employers, resulting in higher turnover rates (Ito, 2003). It is clear from the discussion that both variables are interrelated. Since both arguments seem valid, we will not 
make any assumptions in advance regarding the direction of the relationship between training and turnover behavior. Also the impact of the financial crisis on the training-turnover relationship is unclear. The financial crisis may possibly decrease the training investments made by organizations (Eurofound, 2012), but at the same time training opportunities may become a less important aspect of a job to employees.

Supervisory support. According to social exchange theory, turnover decisions are influenced by relational inducements such as work-related support from the organization, supervisor, and other employees (Maertz et al., 2007; Smith, 2005). Literature suggests that employees are less likely to leave their organization when they feel their work efforts are being supported and facilitated by their supervisor (Dawley et al., 2008; Moos, 1981 in Babin $\&$ Boles, 1996). The importance of the supervisor's support function is derived from his/her role in structuring the work environment, providing information and feedback, and encouraging and valuing employee contributions (Dawley et al., 2008; Griffin et al., 2001; Maertz et al., 2007). This way, supervisors influence employees' feelings of personal wellbeing and may help to reduce burnout (Babin \& Boles, 1996; Kalliath \& Beck, 2001). In general, we hypothesize a negative relationship between supervisor support and employees' turnover intentions.

As suggested at the beginning of our discussion on organizational factors, employees who are satisfied with the various aspects of their job or work environment have a higher likelihood to keep working for the federal government (i.e. lower turnover intention). More specifically, the discussion above showed that a lesser workload, a higher pay level, availability of promotional opportunities, the presence of work-life arrangements, and a sufficient amount of supervisor support will result in lower turnover rates. In addition, prior research suggests that the impact of training on turnover can go either way. In general, we believe that these organizational factors will be less important in predicting employees' turnover intentions during the financial and economic crisis, as people are in the first place looking for job security. Also, the crisis may directly affect some of the factors mentioned here, such as a higher workload, pay cuts, or a decline in training opportunities (Eurofound, 2012). Although we believe that the effects on turnover intention may differ under circumstances of crisis, the complexity of the issue keeps us from formulating clear hypotheses. Overall, given the rising insecurity in employment, "the decision to look for a new job is being re-considered and 'keeping what one has' is the new attitude" (Eurofound, 2012: 41). 


\section{Data}

Our analyses are based on the Federal Employee Viewpoint Survey; in particular three consecutive waves were used: 2006, 2008 and 2010. These three years were used since they allow creating two periods; 2006-2008 which refers to the situation before the crisis and the period 2008-2010 which refers to the crisis period. We thus assume the crisis to have started at the end of 2008. ${ }^{4}$ The Federal Employee Viewpoint Survey is a tool that measures employees' perceptions of whether, and to what extent, conditions which characterize successful organizations are present in their agencies. The survey is administered by the U.S. Office of Personnel Management and targets full-time, permanent employees of departments and large agencies and the small/independent agencies that accept an invitation to participate in the survey. In order to ensure representativeness, weighed data are used in our analyses. The weight indicates the number of employees in the survey population the respondent represents. Information about demographic characteristics, such as gender, race, supervisory status, age, and organization size, are used to develop the weights. ${ }^{5}$

\subsection{Operationalization of variables}

The measure for turnover in the U.S. federal government is based on employees' turnover intentions, rather than actual turnover. Turnover intention is "the cognitive process of thinking of quitting, planning on leaving a job, and the desire to leave the job" (Lambert \& Hogan, 2009: 98). In research, the intention to quit is considered to be the immediate precursor and a good forecaster of actual turnover (e.g. Mobley et al., 1979). Moreover, from the employer's point of view, turnover intention may be more important since employees thinking of quitting may still be persuaded to stay, for example, by changes in the work environment (Dalessio et al., 1986). In the Federal Employee Viewpoint Survey, employees were asked the following question: "Are you considering leaving your organization within the next year and if so, why?" They were given the following options:

\footnotetext{
${ }^{4}$ There are several starting points for the crisis, yet up to September 2008 it had been assumed that governments would always step in to bail out any bank that got into serious trouble. When Lehman brothers went down, the notion that all banks were "too big to fail" no longer held true, with the results that every bank was deemed to be risky, causing the global economy to go into free-fall. It is important to note that the Great Recession officially began earlier (in December 2007, see the National Bureau of Economic Research) however the financial crisis entered an acute phase in September 2008 marked by failures of prominent American and European banks and efforts by the American and European governments to rescue distressed financial institutions, in the United States by passage of the Emergency Economic Stabilization Act of 2008 and in European countries by infusion of capital into major banks. The Dow Jones Industrial Average kept rising until the end of 2007, yet from the beginning of 2008 the average dropped continuously (e.g. from 13.500 in November 2007 to 7.500 in November 2008 ). On September 18, 2008, the Wall Street Journal articulated the fear nearly everyone felt with its headline warning of the "Worst Crisis Since '30s, With No End Yet in Sight." Consequently the crisis became extremely visible starting from 2008. We therefore use 2008 as the starting point of the crisis.

${ }^{5}$ For more information on the survey, see: http://www.fedview.opm.gov/
} 
- No,

- Yes, to retire,

- Yes, to take another job within the federal government,

- Yes, to take another job outside the federal government, or

- Yes, other.

Since we are only looking at movements within the active labor market, retirement as an answer category was dropped from our analyses. Although poor economic conditions could lead people to consider this option in a different way than in prosperous economic times, retirement also raises very different issues than those connected to employees' turnover intentions (Kellough \& Osuna, 1995) and would therefore give biased results. In addition, we also decided to drop the 'yes, other' category as this answer category is difficult to define and can have numerous meanings. ${ }^{6}$ After dropping the two above mentioned categories we constructed a dummy "intention to leave the federal government" based on the remaining categories. This dummy was constructed in the following way:

Dummy equals 0 if the respondent answered:

- No

- Yes, to take another job within the federal government

Dummy is set to 1 if the respondents answered:

- Yes, to take another job outside the federal government

The focus of our paper is on people's intention to leave the federal government as a whole. Therefore, employees who indicated the intent to leave their current organization in order to take another job within the federal government were not included in the turnover category.

The fact that no answer category indicating 'Yes, do not know yet' was included in the survey could be perceived as a weakness of our data. However, we didn't have any influence on the development of the questionnaire and assume that in case respondents had no information on their new job, they would not fill in the question; leading to a missing value. Consequently, we believe our data to be representative.

Table 2 shows the used explanatory variables. In line with literature (e.g. Moynihan \& Landuyt, 2008), all variables used are based on single items. These kinds of variables can be

\footnotetext{
${ }^{6}$ Furthermore, this category was also relatively small: in $20064.2 \%$ of respondents indicated yes, other; in 2008 this figure equaled $3.9 \%$ of all respondents and $3.3 \%$ in 2010 .
} 
perceived as a weakness. Yet single items are often not less reliable than multiple response items (e.g. Bergkvist \& Rossiter, 2007; Gardner et al., 1998; Wanous \& Hundy, 2001). Gardner et al. (1998) even point out that single item measures avoid the risk of aggregating multiple measures whose inter-item correlation is due to common method variance.

All variables are directly implemented from the Federal Employee Viewpoint Survey, except for the variable work-life balance, where we aggregated the separate questions to form an index. ${ }^{7}$ Furthermore, weighted summary statistics are included in the table for the used variables per year. When looking at the main variable of interest 'intention to leave the federal government', we notice that $3.5 \%$ of respondents had the intention of leaving the federal government in 2006, while this number declined in 2008 (3\%) and 2010 (2\%). Furthermore, the difference between 2010 and 2008 was found to be significant while the difference between 2008 and 2006 wasn't. ${ }^{8}$ This finding is an indication that the financial and economic crisis has a negative effect on turnover intention amongst the federal government employees.

Please include Table 2

The linear correlation analysis among regressors is reported in table 3. Not surprisingly, there appears to be a strong correlation between age and years working in the federal government. Furthermore, also the variables promotion, supervisor and training appear to be correlated. Consequently, we test for multicollinearity using the variance inflation factor. The mean VIF equals 1.37 whereby, as expected, the highest VIFs exist for supervisor (1.50) and promotion (1.60). These values indicate that no collinearity exists between the variables or in other words; that the shared variance of the variables is rather low and their discriminant validity is potentially high.

Please include Table 3

\footnotetext{
${ }^{7}$ Cronbach's alpha equals 0.799 .

${ }^{8}$ The weighted means were compared with each other using the lincom command in Stata. The difference between 2010 and 2008 is significant on the 5\% level, while the difference between 2008 and 2006 was not even significant on the $10 \%$ level.
} 


\section{Analysis and results}

As previous sections have shown, we expect that turnover intention $Y$ depends on individual $X$, organizational $U$ and external (such as the financial and economic crisis) $Z$ factors as well as non-observable factors $\varepsilon^{9}$.

$$
Y=\beta_{0}+\sum_{k} \beta_{1} X_{k}+\sum_{k} \beta_{2} U_{k}+\sum_{k} \beta_{6} Z_{k}+\varepsilon
$$

There is however a potential issue with the data which is often ignored by management researchers but is of key importance and can render estimates uninterpretable, namely endogeneity. If the independent variables are correlated with unmodeled variables which also drive other variables in the model, then the independent variables are said to be endogenous. It is not unimaginable that some variables on an organizational or individual level which are not included in our dataset affect both explanatory variables and turnover intention at the same time. For instance the variable 'supervisor' (Overall, how good a job do you feel is being done by your immediate supervisor?), can be argued, in line with literature (e.g. Antonakis et al., 2012), to depend on factors that stem from the employee and the organization. If these factors are omitted from the model and if they predict turnover intention too, the effects of supervisor on turnover intention cannot be correctly estimated.

A possible solution for the issue of endogeneity is the use of a first difference estimator. This, however, requires panel data. The data used here include different years, yet they are not panel data since respondents have not been followed over time. Nevertheless, by calculating means per organization it is possible to link the data per organization over year. This approach allows us to create panel data, be it with some loss of detail. More in particular, panel data is created on the organizational level, not on the individual level. In other words, respondents in 2006, 2008 and 2010 could not be matched and as such we only have meaningful information at the organizational level. In order to ensure representativeness, weights are calculated based on the number of respondents per organization. If we would fail to do so, small organizations would be equally important as large organizations. Using these data we calculate the first difference estimator. For each organization we take the first difference. That is, compute the following:

$$
\Delta y_{i t}=y_{i t^{-}} y_{i t-1}
$$

\footnotetext{
${ }^{9}$ For simplicity, we suppress agency subscripts i.
} 
Whereby -1 refers to the previous period. For 2010 this refers to the year 2008 and for 2008 this refers to the year 2006. We also do this for the explanatory variables:

$$
\Delta y_{i t}=\beta_{0}+\beta_{1}(x)_{i t}+\left(a_{i}+u_{i t}\right)-\left[\beta_{0}+\beta_{1}(x)_{i t-1}+\left(a_{i}+u_{i t-1}\right)\right]
$$

$a_{i}$ is called the fixed effect, or the unobserved effect while $u_{i t}$ is the idiosyncratic error or time-varying error and represents unobserved factors that change over time and effect $y_{i t}$. From the above formula it becomes clear that the fixed effect $a_{i}$ is eliminated. Accordingly, factors that are not in the model and do not vary over time but affect both explanatory variables and turnover intention are removed. These models thus deal with endogeneity and lead to more reliable results. However, since we do not have panel data on the level of the individual but on the level of the organization (averages are calculated per organization), $a_{i}$ can only refer to the organizational fixed effect. As such, this model reduces the issue of endogeneity, yet we have to admit that it is still possible that the model suffers from some degree of endogeneity based on individual characteristics. Subsequently caution is still needed when interpreting results. We estimate this model using OLS. ${ }^{10}$ In Table 5 the results are presented.

\section{Please include Table 4 here}

In Table 4 the results of the first difference estimator are presented. The first column refers to the entire time period 2006-2008-2010. The second refers to 2006-2008 and the third column refers to 2008-2010 and thus the crisis. This makes it possible to analyze differences in the effect of variables across the two time periods. Subsequently we can examine how the crisis affects the impact of other variables on turnover intention.

When examining the first column we notice that the year variable is significant. Note that the year variable is constructed as following; 0 for period 2006-2008 and 1 for period 20082010. The significant effect indicates that in the period after the crisis (during 2008-2010), employees were less likely to leave the current organization. This finding is in line with the literature.

When comparing coefficients across the two time periods (column two and three), we notice differences in the significance levels. Pay has a negative effect on turnover intention

\footnotetext{
${ }^{10}$ No intercept was used.
} 
during the crisis period (2008-2010) but has no effect during the period 2006-08. During the period 2008-10 satisfaction with pay has thus become a significant factor when deciding to leave the federal government; more precisely, people are less inclined to leave their job when they are happy with their pay. Contrary to existing studies (e.g. Pitts, Marvel \& Fernandez, 2011) we initially do not find an effect for pay; however, we notice that this factor becomes important during the crisis period. A possible explanation for the absence of the effect of pay on turnover intention can be linked large sample bias. The literature on turnover intention tends to be based on extremely large samples (e.g. Pitts, Marvel \& Fernandez (2011) is based on 217.00 observations, Moynihan \& Landuyt (2008) is based on 24.000 observations). An extremely large sample will make the standard error extremely small, so that even minuscule distances between the estimate and the null hypothesis become statistically significant (Lin, Lucas \& Shmeli, 2011). This is in turn can explain the significant effect found in literature. Another explanation could be the existence of endogeneity and the use of a first difference estimator. Organization level variables, such as organizational culture, which are not in current models on turnover intention can affect both turnover intention and satisfaction with pay. The use of a First Difference estimator allows to neutralize the effect of organizational culture which in turn can serve as an explanation.

Gender appears to have an effect during the period 2006-08, but has no effect in 2008-10. Based on literature (e.g. Moynihan \& Landuyt, 2008), one would expect that women are less inclined to leave the federal government. Yet, based on this result it appears that the difference between men and women has been eliminated due to the financial and economic crisis. A possible explanation for this finding is the fact that the crisis has made leaving the federal government less attractive for both men and women. For women this was already explained by specific characteristics of the public sector, such as a considerable progress in the representation of women (Choi, 2009; Llorens et al., 2008), lower wage penalties (cf. wage gap between men and women; e.g. Gornick \& Jacobs, 1998; Llorens et al., 2008), and a higher likelihood of finding work-life balance. For men, this is probably due to the effect of the crisis on the private sector. In other words, the alternative for employment within the public sector has become less attractive (e.g. Lewis \& Frank, 2002: 396). A similar effect can be observed for age, before the crisis older people were less likely to leave the federal government, during the crisis the difference between older and younger people has disappeared. Job security becomes not only important for older employees, but as the number of jobs in the private sector and thus the chances on finding another job decrease, it appears to become important for all ages. This is in line with literature (e.g. Eurofound, 2012). 
Although significant for both periods, the effect of training has become significantly less important during the period 2008-10. ${ }^{11}$ If the training needs were assessed during the period 2006-08, respondents were less likely to leave the federal government. Although this still is the case in 2008-10, the strength of this effect has diminished. An explanation lies in the fact that more respondents indicated to agree with the fact that training needs are assessed in 2008 compared to 2006. The assessment of training needs thus improved. Yet, it deteriorated again in 2010. ${ }^{12}$ Thus, during the period 2008-10 there was a significant drop in the number of respondents willing to leave the federal government, yet their training needs were assessed to a lesser extent. Consequently, the effect of training decreased during the period 2008-10. One could also argue that the effect of training opportunities on turnover intention has become smaller, because other factors, such as job security, prevail over personal development.

Furthermore the table indicates that if promotions are based on merit, employees are more likely to leave the current federal government regardless of the crisis. This finding appears to be contra-intuitive; a possible explanation is suggested by Wynen et al. (2013) and Moynihan and Landuyt (2008): employees with greater human capital have a greater ability to find a job elsewhere, and promotions can be considered an indicator of skills and capacity.

Finally, work-life balance appears to significantly affect turnover intention. When employees are satisfied with the arrangements supporting work-life balance, they are less likely to leave their current organization. However, this effect can only be observed when combining all time periods. When examining the different time periods we notice no effect. This finding intuitively makes sense and is also supported by literature (e.g. Battistelli et al., 2013; Smith, 2005, Moynihan \& Landuyt 2008).

\section{Conclusions and discussion}

Most studies examining turnover intention focus on the effect of organizational and individual factors. However, little literature exists analyzing the effect of external factors. Yet, since 2008 the financial and economic situation has changed dramatically leading to a wide range of austerity measures and creating a strong need for more efficient public sector organizations. Since turnover can be considered a negative outcome for organizations, this

\footnotetext{
${ }^{11}$ A formal Hausman test was used to test the hypothesis that regression coefficients across the two time periods were the same. This was achieved by employing the suest and test command in Stata. The difference in the effect of turnover intention over the two examined periods was found to be significant at the $5 \%$ level.

${ }^{12}$ For the original sample of 139,717 observations, the weighted means were compared with each other using the lincom command in Stata. The decrease between 2010 and 2008 is significant on the 1\% level, while the increase between 2008 and 2006 is also significant on the $1 \%$ level.
} 
study's main objective was to understand how the financial and economic crisis affected turnover intention in the U.S. federal government. Three consecutive waves of the Federal Employee Viewpoint Survey were used to examine this relationship. The crisis appeared indeed to have a significant effect on turnover intention.

In order to take the possibility of endogeneity into account, we calculated means per organization and constructed panel data based on the organizational level. Using a first difference estimator, we were able to delete the organizational fixed effects; fixed effects based on the individual level remained. By following this methodology, not only the effects of variables on turnover intention could be estimated but also the difference between the effects of variables across the period 2006-08 and 2008-10 could be examined. Just as for the pooled cross sectional model, the crisis was found to have an effect on turnover intention. Moreover, the effect of pay, gender, age and training were found to differ between the two periods. Pay became more important during the crisis, while the difference between women and men, younger and older employees on turnover intention disappeared. The difference in the effect of training appeared to be caused by a drop in the satisfaction with current training needs assessments. In other words, employees became less satisfied with the assessment of their training needs during the crisis. Furthermore, work-life balance and promotion were found to significantly affect turnover intention. When employees are satisfied with work-life arrangements, they are less likely to leave the current organization. The effect of promotion was, however, a remarkable and rather contra-intuitive finding. If promotions are based on merit, employees are more likely to leave the federal government. A possible explanation could be the fact that promotions can be considered an indicator of skills and capacity and employees with greater human capital have a greater ability to find a job elsewhere.

Overall, these findings suggest two main points of attention for practitioners dealing with turnover in a period of crisis. First of all, employees' pay needs should be assessed as this becomes an even more important element in satisfying and retaining talented employees. In addition, work-life arrangements remain crucial and should be well-thought-out.

An important limitation of our data, however, is the fact that these are originally crosssectional in nature. By calculating means per organization, panel data on an organizational level could be constructed but, as discussed, these do not deal with endogeneity on an individual level. For future research, it would be interesting to also have panel data on an individual level in order to completely reduce the effect of endogeneity. Moreover and also discussed by Wynen, Op de Beeck and Hondeghem (2013), given today's recruiting environment, it would be interesting to investigate the career paths of those from the private 
sector who have sought government careers. Currently, the Federal Employee Viewpoint Survey does not offer such information, yet it would help personnel departments in addressing the recruitment and retention of such employees.

Although this article focused on the U.S. federal government, we believe it can be extended to other, similar governments. There will be cultural and institutional differences, yet we believe the effect of the crisis on staying or leaving the U.S. federal government to be applicable in a broader setting than just the federal government or, geographically, the United States. In our opinion the theories and findings discussed can, consequently, be useful for a wide range of practitioners.

\section{References}

Antonakis, Bendahan, Jacquart \& Lalive (2012). Causality and endogeneity: problems and solutions. In Day V. David (Ed.) The Oxford Handbook of Leadership and Organizations

Appelbaum, B. (2013) Austerity kills government jobs as cuts to budget loom. New York Times. http://www.nytimes.com/2013/02/27/business/as-budget-cuts-loom-austerity-kills-offgovernment-jobs.html?pagewanted=all\& $r=0$

Babin, B. \& Boles, J. (1996). The effect of perceived co-worker involvement and supervisor support on service provider role stress, performance, and job satisfaction. Journal of Retailing. 72: 57-75.

Baldwin, J.N. (1991). Public versus Private Employees: Debunking Stereotypes. Review of Public Personnel Administration. 11(112): 1-27.

Battistelli, A., Portoghese, I., Galletta, M., \& Pohl, S. (2013). Beyond The Tradition: Test of an Integrative Conceptual Model on Nurse Turnover. International Nursing Review. 60(1): 103-111.

Bergkvist, L. \& Rossiter, J.R. (2007). The Predictive Validity of Multiple-item Versus Singleitem Measures of the Same Constructs. Journal of Marketing Research. 44 (May): 175184.

Bertelli, A. (2007). Bureaucratic turnover and democratic governance: Evidence from the U.S. Internal Revenue Service. Journal of Public Administration Research and Theory. 17(2): 235-258. 
Brumby \& Verhoeven (2010). Public expenditure after the global financial crisis. In Canuto, O. \& Giugale, M. (Eds.). A Day After Tomorrow: A Handbook on the Future of Economic Policy in the Developing World. Washington, DC: The World Bank. pp. 193206.

Buelens, M. \& Van den Broeck, H. (2007). An Analysis of Differences in Work Motivation between Public and Private Sector Organizations. Public Administration Review. 67(1). $65-74$.

Cayer, J.N. (1986) Public Personnel Administration in the U.S.

Choi, S. (2009). Diversity in the US Federal Government: Diversity Management and Employee Turnover in Federal Agencies. Journal of Public Administration Research and Theory. 19(3). 603-630.

Cotton, J.L. \& Tuttle, J.M. (1986). Employee turnover: A meta-analysis and review with implications for research. Academy of Management Review. 11. 55-70.

Curry, D., McCarragher, T. \& Dellmann-Jenkins, M. (2005). Training, transfer, and turnover: Exploring the relationship among transfer of learning factors and staff retention in child welfare. Children and Youth Service Review. 27(8). 931-948.

Dalessio, A., Silverman, W. \& Schuck, J. (1986). Paths to Turnover: A Re-analysis and Review of Existing Data on the Mobley, Horner, and Hollingsworth Turnover Model. Human Relations. 39. 245-263.

Dawley, D.D., Andrews, M.C. \& Bucklew, N.S. (2008). Mentoring, supervisor support, and perceived organizational support: what matters most? Leadership \& Organization Development Journal. 29(3). 235-247.

Doering, M. \& Rhodes, S.R. (1996). Intraorganizational and Interorganizational Job Change: A Discriminant Analysis. Journal of Business and Psychology. 11(2). 151-170.

Dowding, K. \& John, P. (2008). The Three Exit, Three Voice and Loyalty Framework: A Test with Survey Data on Local Services. Political Studies. 56. 288-311.

Dullien, S., Kotte J. D., Marquez \& Priewe J. (2011) The Financial and Economic Crisis of 2008-2009 and Developing Countries. UNCTAD report available on: http://unctad.org/en/Docs/gdsmdp20101_en.pdf 
Eurofound (2012). Wages and working conditions in the crisis. European Foundation for the Improvement of Living and Working Conditions. Report available on: http://www.eurofound.europa.eu/docs/ewco/tn1203015s/tn1203015s.pdf

Fairhurst, G. T., \& Antonakis, J. (in press). A Research Agenda for Relational Leadership. In M. Uhl-Bien \& S. Ospina (Eds.), Advancing Relational Leadership Theory: A Conversation among Perspectives. Greenwich, CT: Information Age Publishing.

Galletta, M., I. Portoghese and A. Battistelli, (2011).Intrinsic motivation, job autonomy and turnover intention in the Italian healthcare: The mediating role of affective commitment. Journal of Management Research. 3: 1-19. DOI: 10.5296/jmr.v3i2.619

Gardner, D. G., Cummings, L. L., Dunham, R. B., \& Pierce, J. L. (1998). Single-item versus multiple-item measurement scales: An empirical comparison. Educational and Psychological Measurement. 58: 898-915.

Gornick, J. C., \& Jacobs, J. A. (1998). Gender, the welfare state, and public employment: A comparative study of seven industrialized countries. American Sociological Review. 63(5). 688-710.

Greenhalgh, L., \& Rosenblatt, Z. (1984). Job insecurity: Toward conceptual clarity. Academy of Management Review. 3: 438-448.

Grissom, J.A., Nicholson-Crotty, J. \& Keiser, L. (2012). Does My Boss's Gender Matter? Explaining Job Satisfaction and Employee Turnover in the Public Sector. Journal of Public Administration Research and Theory. 22. 649-673.

Hatum, A. (2010). Next generation Talent management: Talent management to survive turmoil. New York: Palgrave Macmillan.

Holland, P. W. (1986). Statistics and causal inference. Journal of the American Statistical Association, 81(396), 945-960.

Ito, J. K. (2003). Career branding and mobility in the civil service: An empirical study. Public Personnel Management. 32(1). 1-21.

Kalliath, T.J. \& Beck, A. (2001). Is the path to burnout and turnover paved by the lack of supervisory support: a structural equations test. New Zealand Journal of Psychology. 30. 72-78. 
Kellough, J.E., \& Osuna, W. (1995). Cross-agency comparisons of quit rates in the federal service: Another look at the evidence. Review of Public Personnel Administration. 15(4). $58-68$.

Kenny, D. A. (1979). Correlation and causality. New York: Wiley-Interscience.

Kim, S. (2005). Factors affecting state government information technology employee turnover intentions. American Review of Public Administration. 35(2). 137-156.

Lambert, E. \& Hogan, N. (2009). The Importance of Job Satisfaction and Organizational Commitment in Shaping Turnover Intent: A Test of a Causal Model. Criminal Justice Review. 34(1). 96-118.

Lee, S. \& Hong, J.H. (2011). Does Family-Friendly Policy Matter? Testing Its Impact on Turnover and Performance. Public Administration Review. 71(6): 870-879.

Lee, S. \& Whitford, A.B. (2007). Exit, Voice, Loyalty, and Pay: Evidence from the Public Workforce. Journal of Public Administration Research and Theory. 18. 647-671.

Leggatt, T. (1979) Managers in Industry: Their Interorganizational Mobility. Human Relations. 32(10). 851-869.

Lewis, G.B. (1991). Turnover and the quiet crisis in the federal civil service. Public Administration Review. 51(2). 145-155.

Lewis, G.B. \& Frank, S.A. (2002). Who Wants to Work for the Government? Public Administration Review. 62: 395-404.

Llorens, J.J., Wenger, J.B. \& Kellough, J.E. (2008). Choosing Public Sector Employment: The Impact of Wages on the Representation of Women and Minorities in State Bureaucracies. Journal of Public Administration Research and Theory. 18(3). 397-413.

Lin, M., Lucas, H.C. \& Shmueli, G. (2011). Too Big to Fail: Larger Samples and False Discoveries. Robert H. Smith School Research Paper No. RHS 06-068. Available at SSRN: http://ssrn.com/abstract=1336700 or http://dx.doi.org/10.2139/ssrn.1336700

Long, J.S. \& Freese, J. (2006). Regression Models for Categorical Dependent Variables Using Stata. College Station, TX: Stata Press.

Maertz, C.P., Griffeth, R.W., Campbell, N.S. \& Allen, D.G. (2007). The effects of perceived organizational support and perceived supervisor support on employee turnover. Journal of Organizational Behavior. 28. 1059-1075. 
March, J.G. \& Simon, H.A. (1958). Organizations. New York: Wiley.

Martin, T.N. (1979). A Contextual Model of Employee Turnover Intentions. Academy of Management Journal. 22(2). 313-324.

Meier, K. J., \& Hicklin, A. (2008). Employee turnover and organizational performance: Testing a hypothesis from classical public administration. Journal of Public Administration Research and Theory. 18:573-90

Mobley, W., Griffeth, R., Hand, H. \& Meglino, B. (1979). Review and conceptual analysis of the employee turnover process. Psychological Bulletin. 86. 493-522.

Moynihan, D.P. \& Landuyt, N. (2008) Explaining Turnover Intention in State Government: Examining the Roles of Gender, Life Cycle, and Loyalty. Review of Public Personnel Administration. 28(2). 120-143.

Muchinsky, P.M., \& Morrow, P.C. (1980). A multidisciplinary model of voluntary employee turnover. Journal of Vocational Behavior. 17. 263-290.

Pitts, D., Marvel, J. \& Fernandez, S. (2011). So Hard to Say Goodbye? Turnover Intention among U.S. Federal Employees. Public Administration Review, 71 (5):751-60

Smith, B.D. (2005). Job retention in child welfare: Effects of perceived organizational support, supervisor support, and intrinsic job value. Children and Youth Services Review. 27. 153-169.

Sousa-Poza, A. \& Henneberger, F. (2004). Analyzing Job Mobility with Job Turnover Intentions: An International Comparative Study. Journal of Economic Issues. 38(1). 113137.

Stroobants, J. \& Bouckaert, G. (2013). Towards Measurable and Auditable Efficiency Gains in the Flemish Public Sector. Public Organization Review, doi: 10.1007/s11115-0120197-4.

Valcour, P.M. \& Tolbert, P. (2003). Gender, family and career in the era of boundarylessness: determinants and effects of intra- and inter-organizational mobility. International Journal of Human Resource Management. 14(5). 768-787.

Vandenabeele, W. (2008). Government calling: public service motivation as an element in selecting government as an employer of choice. Public administration. 86 (4) : 10891105 . 
Weaver, T.L. (2012). Intent to Exit: What Factors Influence Federal Employees' Decisions to Leave? (dissertation). North Carolina State University. Raleigh, North Carolina.

Warr, P.B., Cook, J.D. \& Wall, T.D. (1979). Scales for the measurements of some work attitudes and aspects of psychological well-being. Journal of Occupational Psychology. 52. 1063-1070.

Wanous, J.P. \& Hudy, M.J. (2001). Single-Item Reliability: A Replication and Extension. Organizational Research Methods. 4(4): 361-375.

Wickramasinghe, V \& Perera G. (2012). HRM practices during the global recession (20082010). Strategic Outsourcing: An International Journal. 5(3): 188-212

Wynen J., Op de Beeck S. \& Hondeghem A. (2013). Interorganizational Mobility within the U.S. Federal Government: Examining the Effect of Individual and Organizational Factors. Public Administration Review. 73(6): 869-881. 


\section{Tables and Figures}

Figure 1 Determinants of Turnover intention

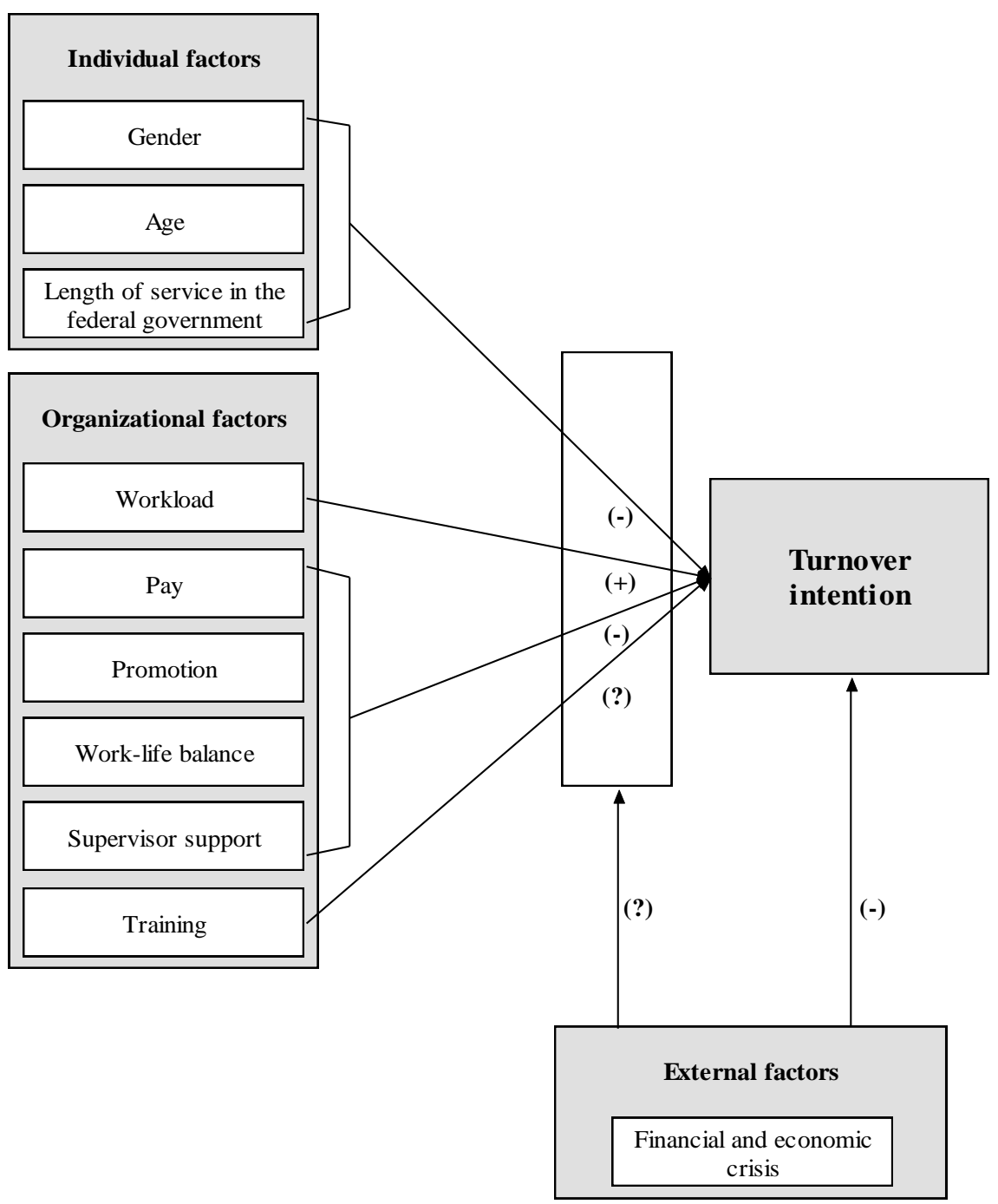




\begin{tabular}{|c|c|c|c|c|c|c|c|c|c|}
\hline \multirow[b]{2}{*}{ Variable } & \multicolumn{3}{|c|}{$2006(n=43,320)$} & \multicolumn{3}{|c|}{$2008(n=36,637)$} & \multicolumn{3}{|c|}{$2010(n=59,760)$} \\
\hline & $\begin{array}{l}\text { Weighted } \\
\text { Mean }\end{array}$ & SD & $\begin{array}{l}\text { Question } \\
\text { code }\end{array}$ & $\begin{array}{l}\text { Weighted } \\
\text { Mean }\end{array}$ & SD & $\begin{array}{l}\text { Question } \\
\text { code }\end{array}$ & $\begin{array}{l}\text { Weighted } \\
\text { Mean }\end{array}$ & SD & $\begin{array}{l}\text { Question } \\
\text { code }\end{array}$ \\
\hline Intention to leave the federal fovernment & 0.0350 & 0.00273 & dleaving & 0.0303 & 0.00194 & dleaving & 0.0202 & 0.00376 & dleaving \\
\hline Gender & 0.374 & 0.00774 & dsex & 0.384 & 0.00632 & dsex & 0.418 & 0.00998 & dsex \\
\hline Age & 2.310 & 0.0126 & dagegrp & 2.282 & 0.0115 & dagegrp & 2.271 & 0.0217 & dagegrp \\
\hline $\begin{array}{l}\text { Years working for the federal } \\
\text { government }\end{array}$ & 4.075 & 0.0163 & dfedten & 4.601 & 0.0214 & dfedten & 4.067 & 0.0389 & dfedten \\
\hline Pay & 3.643 & 0.0154 & Q61 & 3.593 & 0.0139 & Q62 & 3.679 & 0.0208 & Q70 \\
\hline Promotion & 2.994 & 0.0188 & Q22 & 2.979 & 0.0151 & Q22 & 3.079 & 0.0205 & Q22 \\
\hline Work/Life balance & 3.361 & 0.0145 & Q71 & 3.384 & 0.0127 & Q72 & 3.289 & 0.0142 & Q73-Q78 \\
\hline Training & 3.372 & 0.0166 & Q50 & 3.432 & 0.0131 & Q51 & 3.493 & 0.0190 & Q18 \\
\hline Workload & 3.355 & 0.0177 & Q17 & 3.365 & 0.0134 & Q17 & 3.474 & 0.0173 & Q10 \\
\hline Supervisor & 3.850 & 0.0171 & Q9 & 3.835 & 0.0137 & Q9 & 3.996 & 0.0199 & Q52 \\
\hline
\end{tabular}

Question code refers to the question code used in the Federal Employee Viewpoint survey which can freely be consulted online at: http://www.fedview.opm.gov/, more detailed information per question can be found here. 
Table 2 Correlation matrix

\begin{tabular}{|c|c|c|c|c|c|c|c|c|c|c|c|c|c|c|}
\hline Variables & & $(1)$ & $(2)$ & $(3)$ & $(4)$ & $(5)$ & $(6)$ & $(7)$ & $(8)$ & (9) & $(10)$ & $(11)$ & $(12)$ & $(13)$ \\
\hline Intention to leave the federal government & (1) & 1 & & & & & & & & & & & & \\
\hline Gender & (2) & -0.0431 & 1 & & & & & & & & & & & \\
\hline Age & (3) & -0.0542 & 0.0009 & 1 & & & & & & & & & & \\
\hline Yearsfed & (4) & -0.0573 & 0.0731 & 0.5823 & 1 & & & & & & & & & \\
\hline Workload & $(5)$ & -0.0785 & -0.0151 & -0.0310 & -0.0739 & 1 & & & & & & & & \\
\hline Supervisor & (6) & -0.0853 & -0.0228 & 0.0080 & -0.0255 & 0.2975 & 1 & & & & & & & \\
\hline Pay & (7) & -0.1312 & 0.0102 & 0.0144 & 0.0118 & 0.2532 & 0.2899 & 1 & & & & & & \\
\hline Promotion & (8) & -0.0992 & -0.0135 & 0.0126 & 0.0013 & 0.2965 & 0.5033 & 0.3920 & 1 & & & & & \\
\hline Worklife & (9) & -0.0880 & 0.0458 & 0.0328 & 0.0236 & 0.2416 & 0.2596 & 0.3044 & 0.3335 & 1 & & & & \\
\hline Training & (10) & -0.1041 & 0.0207 & -0.0030 & -0.0251 & 0.3525 & 0.4552 & 0.2892 & 0.4755 & 0.3546 & 1 & & & \\
\hline 2006 & (11) & 0.0313 & -0.0302 & 0.0165 & -0.0472 & -0.0337 & -0.0381 & -0.0026 & -0.0197 & 0.0217 & -0.0427 & 1 & & \\
\hline 2008 & (12) & 0.0121 & -0.0151 & -0.0016 & 0.1365 & -0.0253 & -0.0426 & -0.0296 & -0.0251 & 0.0367 & -0.0066 & -0.3594 & 1 & \\
\hline 2010 & (13) & -0.0387 & 0.0402 & -0.0135 & -0.0753 & 0.0523 & 0.0711 & 0.0279 & 0.0395 & -0.0513 & 0.0442 & -0.5916 & -0.5398 & 1 \\
\hline
\end{tabular}

Note that this correlation matrix is based on 139717 observations. 
Table 3 First difference estimates

\begin{tabular}{|c|c|c|c|}
\hline & $\begin{array}{c}\text { Period 2006- } \\
\quad 08-10\end{array}$ & $\begin{array}{l}\text { Period 2006- } \\
08\end{array}$ & $\begin{array}{c}\text { Period } 2008- \\
10\end{array}$ \\
\hline VARIABLES & $\beta$ & $\beta$ & $\beta$ \\
\hline \multirow[t]{2}{*}{ diff_year } & $-0.0111^{* * * *}$ & & \\
\hline & $(0.00196)$ & & \\
\hline \multirow[t]{2}{*}{ diff_pay } & -0.0127 & -0.00456 & $-0.0567 * * *$ \\
\hline & (0.00929) & $(0.0120)$ & (0.00799) \\
\hline \multirow[t]{2}{*}{ diff_workload } & -0.00889 & -0.0151 & 0.00885 \\
\hline & $(0.00962)$ & $(0.0144)$ & $(0.00884)$ \\
\hline \multirow[t]{2}{*}{ diff_promotion } & $0.0261 *$ & $0.0404 *$ & $0.0218^{*}$ \\
\hline & $(0.0125)$ & $(0.0173)$ & $(0.00955)$ \\
\hline \multirow[t]{2}{*}{ diff_gender } & -0.00664 & $-0.0182^{*}$ & 0.000264 \\
\hline & $(0.00489)$ & (0.00799) & $(0.00552)$ \\
\hline \multirow[t]{2}{*}{ diff_age } & $-0.0222 *$ & $-0.0287 *$ & -0.00521 \\
\hline & (0.00918) & $(0.0129)$ & $(0.0110)$ \\
\hline \multirow[t]{2}{*}{ diff_yearsfed } & -0.000405 & 0.000135 & $0.00227 *$ \\
\hline & $(0.000932)$ & $(0.00137)$ & (0.00119) \\
\hline \multirow[t]{2}{*}{ diff_worklife } & $-0.0175 * *$ & -0.0233 & -0.00945 \\
\hline & $(0.00591)$ & $(0.0145)$ & $(0.00573)$ \\
\hline \multirow[t]{2}{*}{ diff_training } & $-0.0365 * * *$ & $-0.0503 * * *$ & $-0.0169^{*}$ \\
\hline & $(0.00658)$ & $(0.0103)$ & $(0.00797)$ \\
\hline \multirow[t]{2}{*}{ diff_supervisor } & -0.0114 & -0.0255 & -0.0153 \\
\hline & $(0.0118)$ & $(0.0179)$ & $(0.0130)$ \\
\hline Observations & 423 & 207 & 216 \\
\hline R-squared & 0.422 & 0.318 & 0.595 \\
\hline
\end{tabular}

Robust standard errors in parentheses $* * * \mathrm{p}<0.001, * * \mathrm{p}<0.01, *$ $\mathrm{p}<0.05$ 